Синецкая А. А., Кизиль Е. В.

НАПРАВЛЕНИЯ УЛУЧШЕНИЯ ХОЗЯЙСТВЕННОЙ ДЕЯТЕЛЬНОСТИ ПРЕДПРИЯТИЙ ЖЕЛЕЗНОДОРОЖНОГО ТРАНСПОРТА

(НА ПРИМЕРЕ ООО «ЛОКОТЕХ-СЕРВИС»)

Синецкая А. А., Кизиль Е. В.

A. A. Sinetskaya, E. V. Kizil'

НАПРАВЛЕНИЯ УЛУЧШЕНИЯ ХОЗЯЙСТВЕННОЙ ДЕЯТЕЛЬНОСТИ

ПРЕДПРИЯТИЙ ЖЕЛЕЗНОДОРОЖНОГО ТРАНСПОРТА

(НА ПРИМЕРЕ ООО «ЛОКОТЕХ-СЕРВИС»)

\title{
DIRECTIONS OF IMPROVEMENT OF ECONOMIC ACTIVITIES OF THE RAILWAY TRANSPORT ENTERPRISES (FOR EXAMPLE «LOCOTEH-SERVICE»)
}

Синецкая Алина Александровна - студентка магистратуры направления 38.04.01 «Экономика» Комсомольского-на-Амуре государственного университета (Россия, Комсомольск-на-амуре); 681013, Хабаровский край, г. Комсомольск-на-Амуре, пр. Ленина, 27; тел.: +7 (924) 319-86-56. E-mail: Sinechkaya_alina@mail.ru.

Alina A. Sinetskaya - master's student of the direction 38.04.01 «Economics» of Komsomolsk-on-Amur State University (Russia, Komsomolsk-on-Amur); 681013, Khabarovsk territory, Komsomolsk-on-Amur, 27 Lenin str.; tel.: +7 (924) 319-86-56. E-mail: Sinechkaya_alina@mail.ru.

Кизиль Елена Витальевна - кандидат экономических наук, доцент, доцент кафедры экономики, финансов и бухгалтерского учёта Комсомольского-на-Амуре государственного университета (Россия, Комсомольскна-Амуре); 681013, Хабаровский край, г. Комсомольск-на-Амуре, пр. Ленина, 27; тел.: +7 (914) 179-42-20. E-mail: kisil_ev@mail.ru.

Ms. Elena V V. Kizil' - candidate of economic Sciences, associate Professor, associate Professor, Department of Economics, Finance and accounting, Komsomolsk-on-Amur State University (Russia, Komsomolsk-on-Amur); 681013, Khabarovsk territory, Komsomolsk-on-Amur, 27 Lenin str.; tel.: + 7 (914) 179-42-20. E-mail: kisil_ev@mail.ru.

Аннотация. В работе рассмотрено современное состояние парка тягового подвижного состава ООО «ТМХСервис» и представлены направления дальнейшего совершенствования функционирования железнодорожной отрасли на примере внедрения системы «Умный локомотив».

Summary. The paper considers the current state of the fleet of traction rolling stock of TMH-Service LLC and presents the directions of further improvement of the railway industry on the example of the introduction of the «Smart locomotive» system.

Ключевые слова: диджитализация производственных процессов, повышение производительности тягового подвижного состава.

Key words: digitalization of production processes, increasing the productivity of traction rolling stock.

УДК:338

Одной из главных задач ООО «ТМХ-Сервис» является содержание в технически исправном состоянии локомотивного парка. При несоблюдении требований к содержанию парка компания вынуждена выплатить штраф ОАО «Российские железные дороги» $(\mathrm{OAO}$ «РЖ $)$. Для решения этой задачи необходимо повышение надёжности локомотивов и качества ремонта, что позволит снизить количество отказов технических средств локомотивов на линии и внеплановых ремонтов тягового подвижного состава [1].

В 2014 году ООО «ТМХ-Сервис» (входит в «ЛокоТех-Сервис») заключило контракт с ОАО «РЖД» по итогам аукциона на полное сервисное обслуживание 14799 локомотивов.

Филиал «Дальневосточный» принял на обслуживание 2108 локомотивов, что составляет 14,2 \% от общего количества единиц техники обслуживаемого парка [1]. 


\section{Учёные записки}

Комсомольского-на-Амуре государственного технического университета

Плюсом к принятому в оборот парку (7 \% от общего количества всех машин) в 2017 году филиал «Дальневосточный» увеличивает наполняемость сервисного парка на 9,8 \%, доводя количество локомотивов до 2316 единиц (15,6 \% от общего количества единиц обслуживаемого парка локомотивов). На обслуживании у Сервисного локомотивного депо «Амурское» находятся 197 локомотивов (1,3\% от общего количества единиц обслуживаемого парка локомотивов).

Внеплановые ремонты вследствие непредвиденных выходов из строя технических средств тягового подвижного состава требуют незапланированных финансовых вложений, что является убыточным для предприятия.

Проведя факторный анализ по безопасности движения в Сервисном локомотивном депо «Амурское» за четыре года с момента заключения договора ООО «ТМХ-Сервис» с ОАО «РЖД», вывели общее количество случаев неплановых ремонтов тягового подвижного состава приписки ТЧЭ-9, Комсомольск-на-Амуре и распределили их по ответственности за виновными в допущении данных случаев предприятиями. Данные приведены на рис. 1.

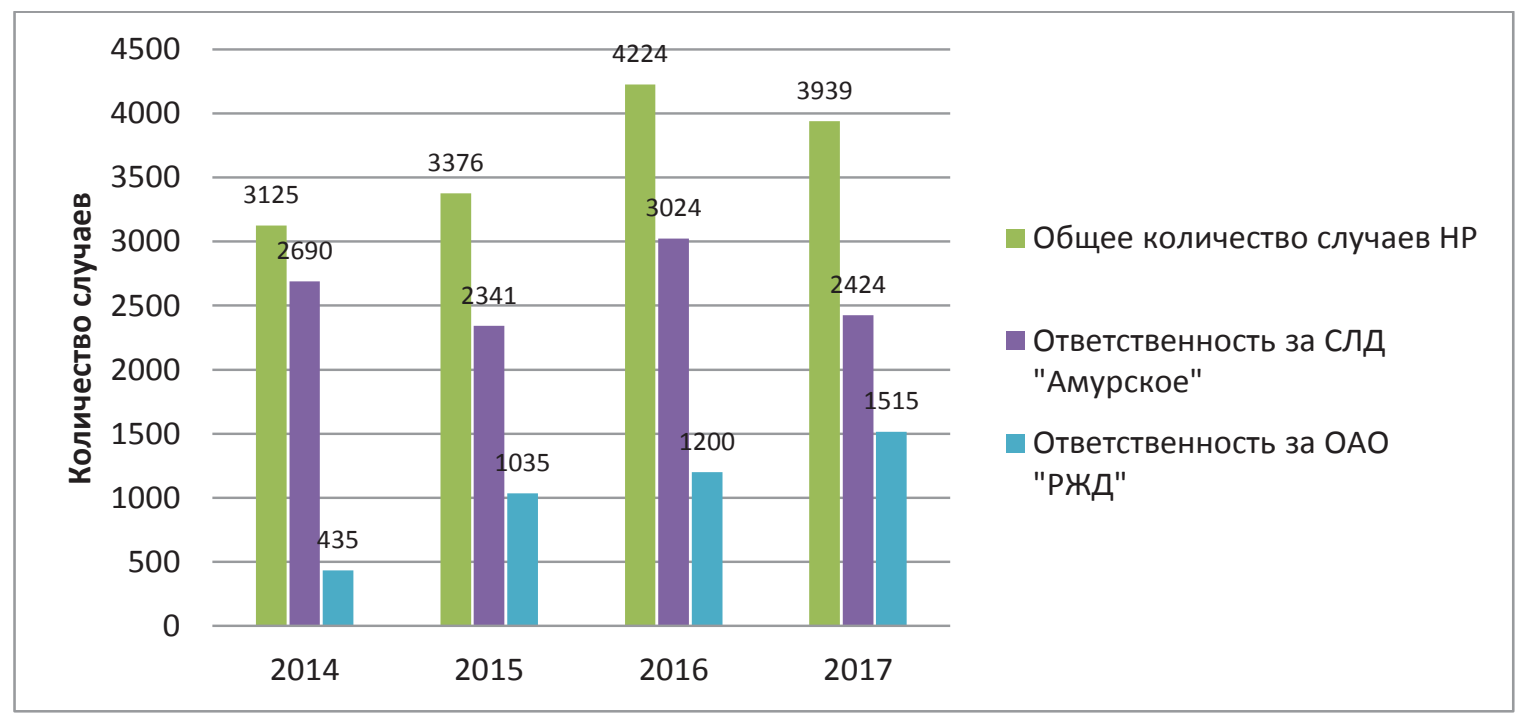

Рис. 1. График распределения случаев внеплановых ремонтов тягового подвижного состава по ответственности за виновным предприятием

C помощью факторного анализа были проанализированы финансовые затраты на проведение внеплановых ремонтов тягового подвижного состава в Сервисном локомотивном депо «Амурское» за 2014-2017 гг. Данные представлены в табл. 1 и на рис. 2.

Таблица 1

Финансовые затраты на внеплановый ремонт тягового подвижного состава

\begin{tabular}{|c|c|c|c|c|}
\hline \multicolumn{5}{|c|}{ Финансовые затраты на внеплановый ремонт тягового подвижного состава, руб. } \\
\hline \multirow{2}{*}{ Название организации } & 2014 & 2015 & 2016 & 2017 \\
\cline { 2 - 5 } & 54495788 & 220692339 & 299681780 & 202982410 \\
\hline СЛД «Амурское» & 71324 & 23279595 & 40524725 & 36742407 \\
\hline ОАО «РЖД» &
\end{tabular}

Одной из базовых задач повышения результативности работы филиала стала программа повышения надёжности. Совместно с ОАО «РЖД» филиал реализует двухгодичную программу восстановления системы ремонта ТР-2, улучшения состояния локомотивов по картам оздоровления, повышения надёжности за счёт ремонта линейного оборудования на заводах при выполнении 
Синецкая А. А., Кизиль Е. В.

НАПРАВЛЕНИЯ УЛУЧШЕНИЯ ХОЗЯЙСТВЕННОЙ ДЕЯТЕЛЬНОСТИ ПРЕДПРИЯТИЙ ЖЕЛЕЗНОДОРОЖНОГО ТРАНСПОРТА

(НА ПРИМЕРЕ ООО «ЛОКОТЕХ-СЕРВИС»)

подъёмочного ремонта ТР-3. В рамках обширной инвестпрограммы завершилось строительство цеха ТО-3 в пункте технического обслуживания «Комсомольск-Сортировочный». Сервисное отделение «Новый Ургал» оснащается новым оборудованием для ремонта, усиливаются производственные мощности пунктов ремонта в Советской Гавани и Высокогорном. Большие средства вкладываются в депо «Тында», производится обкатка ремонта ТР-600 тепловозов серии 2ТЭ25А [1].

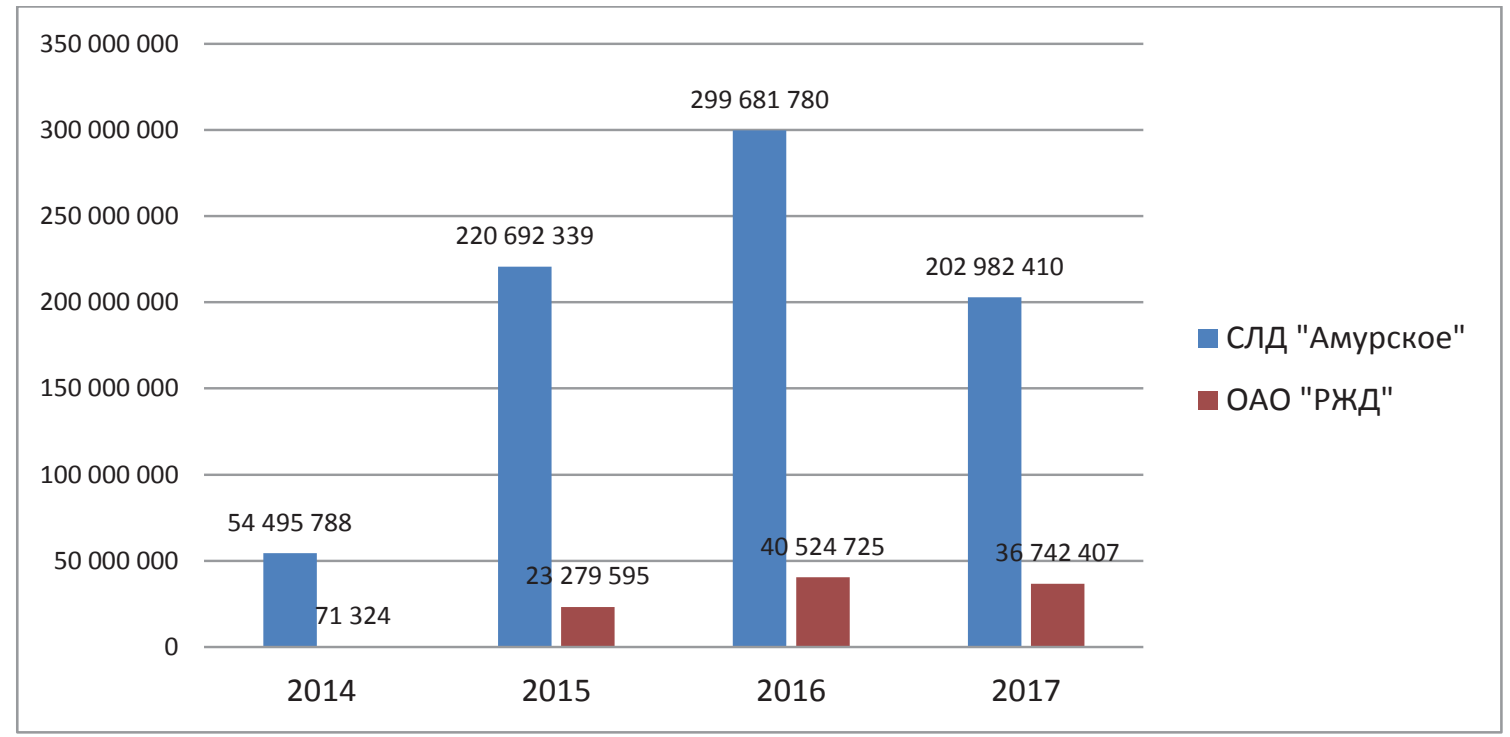

Рис. 2. Диаграмма финансовых затрат на внеплановый ремонт тягового подвижного состава

Локомотивный парк ОАО «РЖД» обновляется, из эксплуатации выводятся локомотивы устаревших серий.

Внедряемая компанией «ЛокоТех-Сервис» с 2016 года система «Умный локомотив» поможет предотвратить нештатные ситуации, а именно позволит заблаговременно выявить предотказные состояния оборудования и оперативно принять меры для недопущения отказа локомотива на линии, сократит затраты на внеплановые ремонты тягового подвижного состава, устранит факты нарушений режимов эксплуатации локомотивов.

Уже сегодня можно создать целый парк «умных локомотивов», отслеживая состояние каждой единицы тягового подвижного состава в онлайн-режиме и выявляя предотказные состояния, не дожидаясь серьёзных поломок и тяжёлого ремонта с большими финансовыми затратами. Это повысит производительность локомотивного комплекса и сократит расходы как сервисных предприятий группы компаний «ЛокоТех-Сервис», так и ключевого её клиента - ОАО «РЖД» [2].

В «ЛокоТех-Сервис» рассчитывают на то, что диджитализация производственных процессов и анализа данных с локомотивов приведут к снижению потерь минимум на 30 \%, что позволит существенно оптимизировать расходы на локомотивный парк ключевого клиента - ОАО «РЖД». Значительный эффект от внедрения программы планируется достичь уже к концу 2018 года. Это станет возможным за счёт повышения коэффициента технической готовности (КТГ) тягового подвижного состава (КТГ определяет долю исправных локомотивов в общем парке железных дорог), снижения числа внеплановых ремонтов и повышения эффективности системы сервисного обслуживания [3].

График расчёта срока окупаемости проекта «Умный локомотив» представлена на рис. 3. Построив график, можно сделать вывод о том, что срок окупаемости проекта составит менее трёх лет, что сделает его экономически привлекательным [3].

Таким образом, дальнейшее совершенствование хозяйственной деятельности предприятий железнодорожного транспорта мы связываем с техническим перевооружением системы управле- 


\section{Учёные записки}

Комсомольского-на-Амуре государственного технического университета

ния ремонтами тягового подвижного состава локомотивных депо путём внедрения системы «Умный локомотив», позволяющей оптимизировать процесс эксплуатации парка локомотивов.

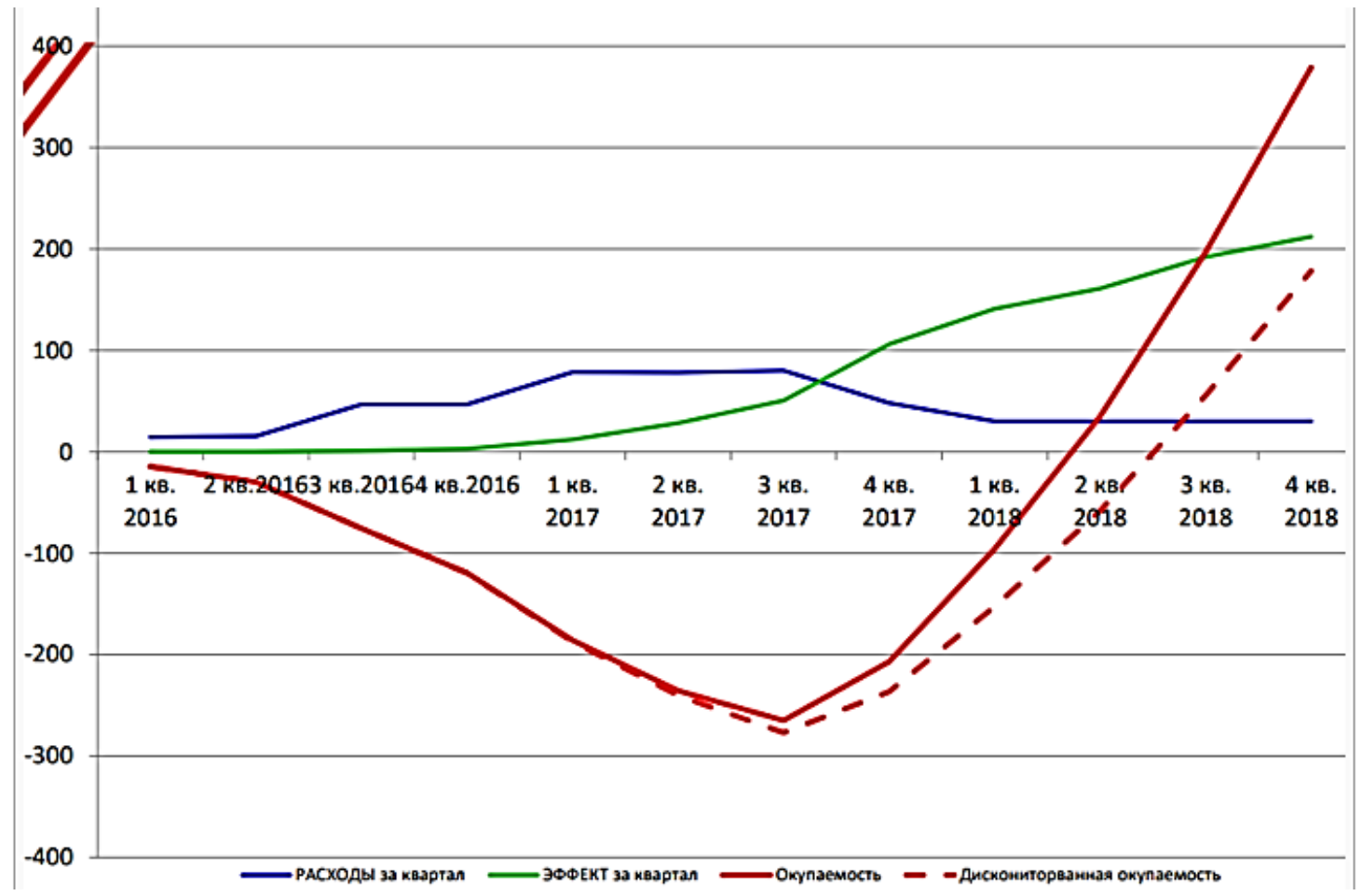

Рис. 3. График расчёта срока окупаемости проекта «Умный локомотив»

\section{ЛИТЕРАТУРА}

1. Чагин, В. Эффективность доказана делом / В. Чагин // Дальневосточная магистраль. - 2017. № 35 .

2. Сам себе контролёр // Гудок. - 2017.

3. Tadviser. Бизнес-конференция. Проект «Умный локомотив» [Электронный ресурс]. - Режим доступа: http://www.tadviser.ru/index.php / (дата обращения: 24.05.2018). 